\title{
Long-Term Cyclophosphamide Treatment in a Case with Serpiginous Choroiditis
}

\author{
Ozlem G. Sahin
}

Department of Ophthalmology, Middle East Technical University Health Center Ankara, Turkey

\section{Key Words}

Alkylating agent $\cdot$ Cyclophosphamide $\cdot$ Serpiginous choroiditis

\begin{abstract}
Purpose: To report the effect of long-term therapy with the alkylating agent cyclophosphamide in a case with serpiginous choroiditis and thus to contribute to the previously reported few cases showing the beneficial effect of long-term cyclophosphamide therapy for serpiginous choroiditis.

Procedures: Oral cyclophosphamide therapy for 12 months in a case with unilateral active serpiginous choroiditis.

Results: The active lesion responded well to long-term therapy with cyclophosphamide without recurrences and significant systemic side-effects.

Conclusions: Long-term therapy with cyclophosphamide for serpiginous choroiditis is effective for improving vision and preventing recurrences.
\end{abstract}

\section{Introduction}

Serpiginous choroiditis is considered a bilateral inflammatory disorder of the retinal pigment epithelium (RPE) and the choroid [1]. It is reported to start with irregular graywhite patches representing subretinal infiltration, which show a propensity to development near the optic disc or in the posterior pole [1]. A combination of immunosuppressives with oral prednisone is recommended to salvage vision in serpiginous choroiditis [2]. We report a case with serpiginous choroiditis treated successfully with long-term oral cyclophosphamide therapy.

\section{Case Report}

A 58-year-old white male presented with sudden onset of blurred vision in his left eye (OS). The best-corrected visual acuity of the right eye (OD) was 20/400, and OS 20/40 with normal anterior segments. The right fundus showed disciform macular and peripapillary chorioretinal scars (fig. 1). The 
left fundus disclosed a paramacular subretinal infiltrate with creamy yellow, fluffy margins and peripapillary chorioretinal scars (ig. 2). Vitreous was clear in both eyes.

Fluorescein angiogram (FA) OD revealed blockage of the fluoresence corresponding to the areas of RPE hypertrophy with staining along the edges (fig. 3). FA OS disclosed early blockage of fluorescein followed by leakage and staining corresponding to the paramacular area (fig. $4 \mathrm{a}, \mathrm{b})$. The patient's past medical history was significant for a short course of treatment with oral prednisone because of sudden onset of blurred vision OD 9 months ago. Tuberculosis, syphilis and toxoplasmosis were considered in the differential diagnosis. Blood tests for uveitis work-up, computerized tomography of the chest, and tuberculin skin test were negative. The diagnosis of serpiginous choroiditis was considered due to bilateral involvement of the peripapillary area and the posterior pole, absence of vitreous cells and negative laboratory work-up. Treatment with oral cyclophosphamide $2 \mathrm{mg} / \mathrm{kg} /$ day and prednisone 1 $\mathrm{mg} / \mathrm{kg} /$ day were initiated. Prednisone dose was tapered gradually and discontinued. Fundus examination OS at the 3rd month of cyclophosphamide therapy showed increased pigmentation with descrete borders of the previously active paramacular infiltrate (fig. 5 ). FA OS revealed mottled hyperfluorescence due to pigment clumping in the early and late frames (fig. 6a, b). The patient received cyclophosphamide for 12 months with no recurrence in either eye, and improving of vision OS to 20/20. Best-corrected visual acuity OD remained 20/400.

Cyclophosphamide was discontinued after 12 months due to microscopic hematuria. The patient is currently being followed up. He has been on no medication for 6 months without recurrence in either eye.

\section{Discussion}

The diagnosis and management of serpiginous choroiditis is considered to present a challenge $[3,4]$. Ocular involvement in serpiginous choroiditis is described as usually bilateral, rarely multifocal, and primarily involving the posterior pole, especially around the optic disc and extending contiguosly to the macula [3]. No patient with serpiginous choroiditis is reported to present with vitritis [3]. However, tuberculous, serpiginous-like choroiditis is reported to show significant vitritis and often presents with multifocal lesions in the posterior pole and periphery [3]. The clinical presentation of our case is most likely compatible with serpiginous choroiditis because of the absence of vitreous cells, bilateral involvement of the peripapillary area and the posterior pole, negative uveitis work-up including blood tests, computerized tomography of the chest, and tuberculin skin test.

A combination of azathioprine, cyclosporin, and prednisone therapy has been reported to provide rapid remission in all 5 patients treated [5]. However, the same source also reported the recurrence of choroidal inflammation immediately after cessation of the immunosuppressive therapy [5]. Long-term immunosuppressive therapy is indicated to prolong remission and preserve vision in patients with serpiginous choroiditis [4]. Successful treatment with an alkylating agent, either chlorambucil or cyclophosphamide has been reported in 9 patients with active, vision-threatening serpiginous choroiditis [4]. Our patient had initially been treated with a short course of oral prednisone for blurred vision OD. However, the treatment had not been successful and resulted in the formation of a disciform macular scar. Cyclophosphamide treatment combined with prednisone was considered as the first-line treatment for active serpiginous lesion OS for this case due to profound loss of vision OD. Unilateral active choroiditis OS responded well to long-term oral cyclophosphamide therapy without formation of either choroidal neovascularization or disciform macular scar. The patient received no adjunctive therapy other than a short course of oral prednisone. Successful resolution of the active lesion was achieved in 3 months of cyclophosphamide therapy. However, the treatment was continued because of 
the proximity of the lesion to the macula, and because of profound loss of vision OD. The following side-effects of cyclophosphamide therapy have been reported: hemorrhagic cystitis, bone marrow suppression, anemia, sterility and secondary malignancy [6]. Our patient experienced microscopic hematuria after 12 months of therapy. Treatment was discontinued because of the possibility of urinary bladder carcinoma. Alternative treatment with biologic therapy, such as interferon alpha-2a, has been recommended for severe cases who were unable to continue therapy with alkylating agents [7]. Interferon alpha-2a was considered in case of recurrences for our case. However, the patient had no recurrence during 6 months of follow-up. Since there were few reported cases showing the efficacy of long-term therapy with cyclophosphamide in serpiginous choroiditis, we believe this case will contribute to the understanding of the beneficial effect of long-term cyclophosphamide therapy for improving vision and preventing recurrences without significant systemic side-effects.

\section{Disclosure Statement}

The author did not receive grants or funds in support of the study.

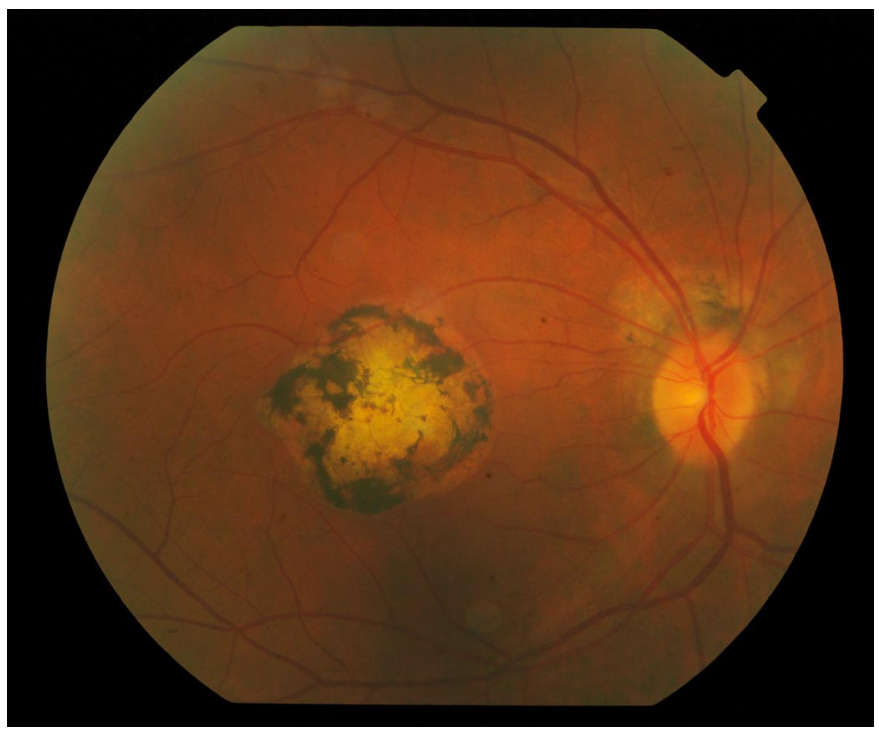

Fig. 1. Color fundus photograph of disciform macular and peripapillary chorioretinal scars in the right eye. 


\begin{tabular}{c|l|l|l}
$\begin{array}{c}\text { Case Reports in } \\
\text { Ophthalmology }\end{array}$ & $\begin{array}{l}\text { Case Rep Ophthalmol 2010;1:71-76 } \\
\text { DOl: 10.1159/000321401 }\end{array}$ & $\begin{array}{l}\text { Published online: } \\
\text { October 5, 2010 }\end{array}$ & $\begin{array}{l}\text { O 2010 S. Karger AG, Basel } \\
\text { ISSN 1663-2699 } \\
\text { www.karger.com/cop }\end{array}$ \\
\hline
\end{tabular}

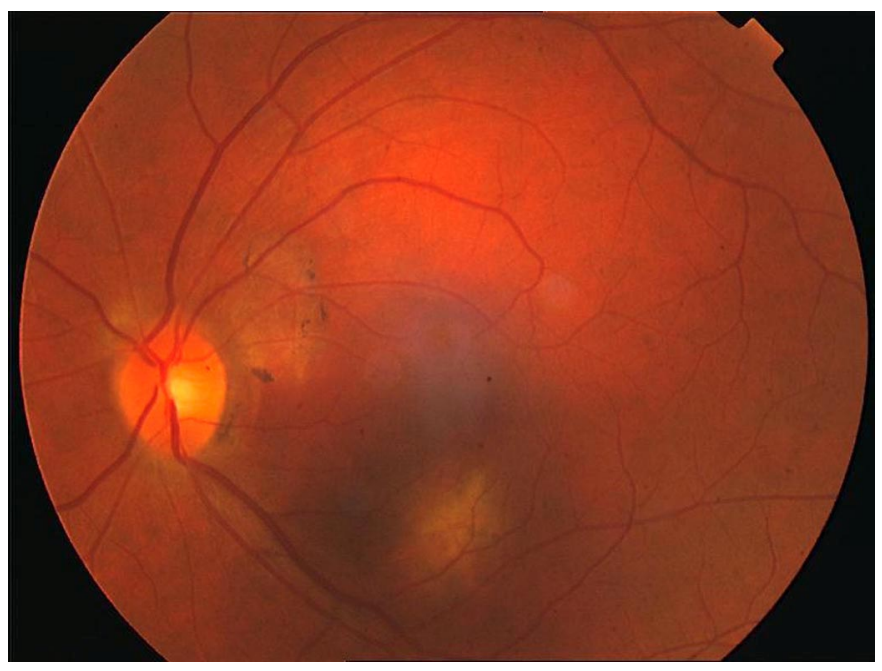

Fig. 2. Color fundus photograph of paramacular subretinal infiltrate and peripapillary chorioretinal scars in the left eye.

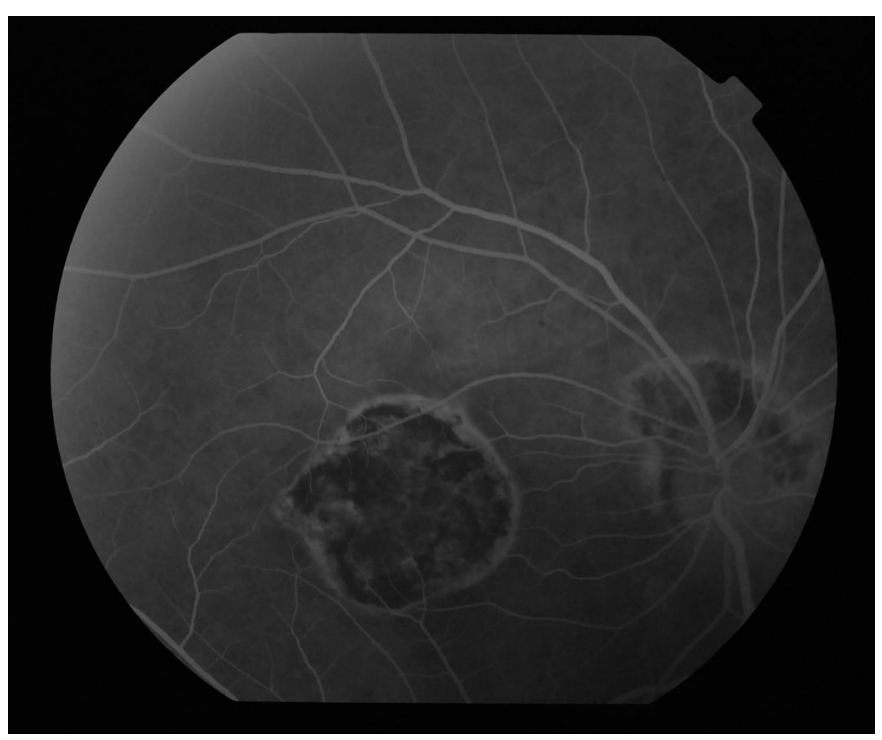

Fig. 3. Fluorescein angiogram of the right eye. Note the blockage of the fluorescence corresponding to the areas of RPE hypertrophy with staining along the edges. 


\begin{tabular}{c|l|l|l}
$\begin{array}{c}\text { Case Reports in } \\
\text { Ophthalmology }\end{array}$ & $\begin{array}{l}\text { Case Rep Ophthalmol 2010;1:71-76 } \\
\text { DOI: 10.1159/000321401 }\end{array}$ & $\begin{array}{l}\text { Published online: } \\
\text { October 5, 2010 }\end{array}$ & $\begin{array}{l}\text { O 2010 S. Karger AG, Basel } \\
\text { ISSN 1663-2699 } \\
\text { www.karger.com/cop }\end{array}$ \\
\hline
\end{tabular}

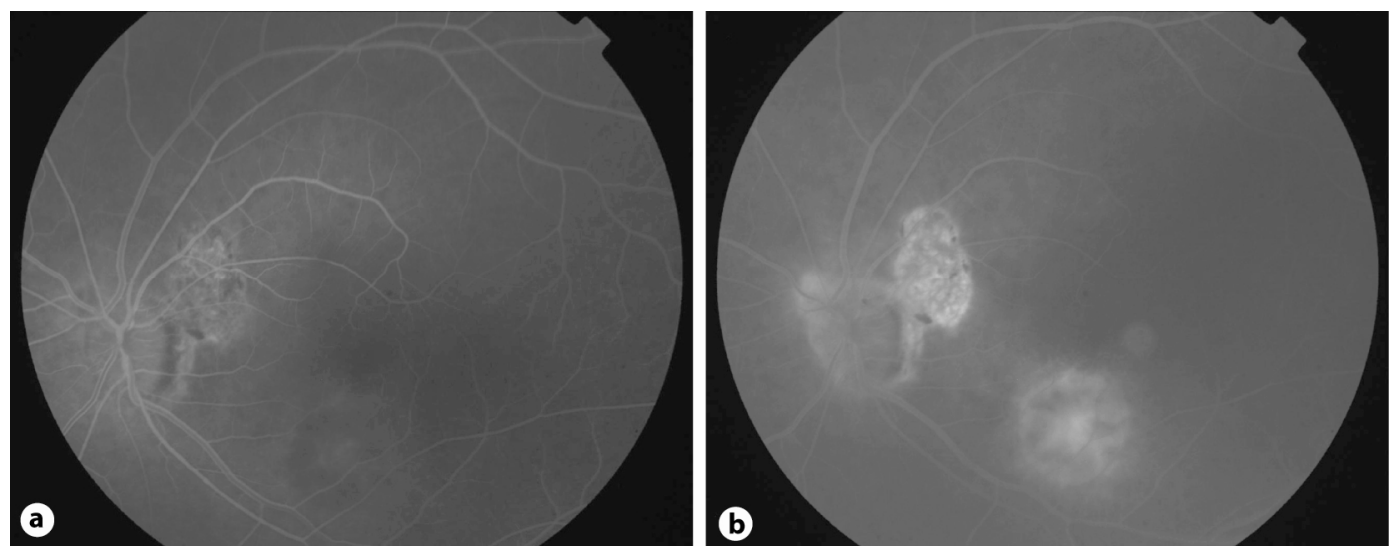

Fig. 4. a, b Fluorescein angiogram of the left eye. Note the early blockage of fluorescein followed by leakage and staining corresponding to the paramacular area.

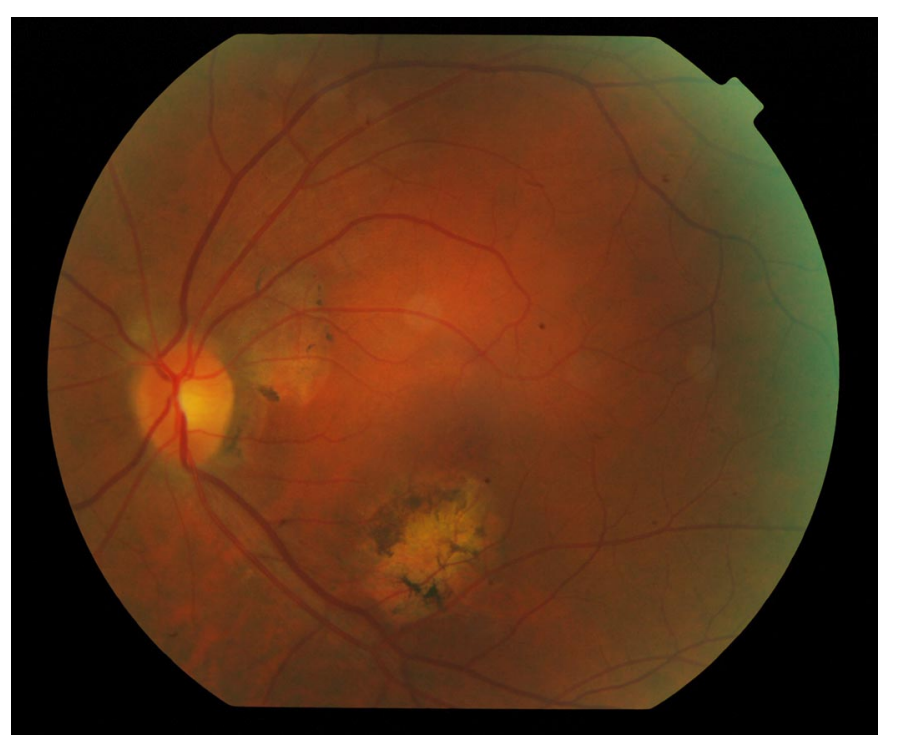

Fig. 5. Color fundus photograph of the left eye at the 3rd month of cyclophosphamide therapy. Note the increased pigmentation with discrete borders of the previously active paramacular infiltrate. 


\begin{tabular}{l|l|l|l} 
Case Reports in & $\begin{array}{l}\text { Case Rep Ophthalmol 2010;1:71-76 } \\
\text { DOI: 10.1159/000321401 }\end{array}$ & $\begin{array}{l}\text { Published online: } \\
\text { October 5, 2010 }\end{array}$ & $\begin{array}{l}\text { ○ 2010 S. Karger AG, Basel } \\
\text { ISSN 1663-2699 } \\
\text { www.karger.com/cop }\end{array}$ \\
\hline
\end{tabular}
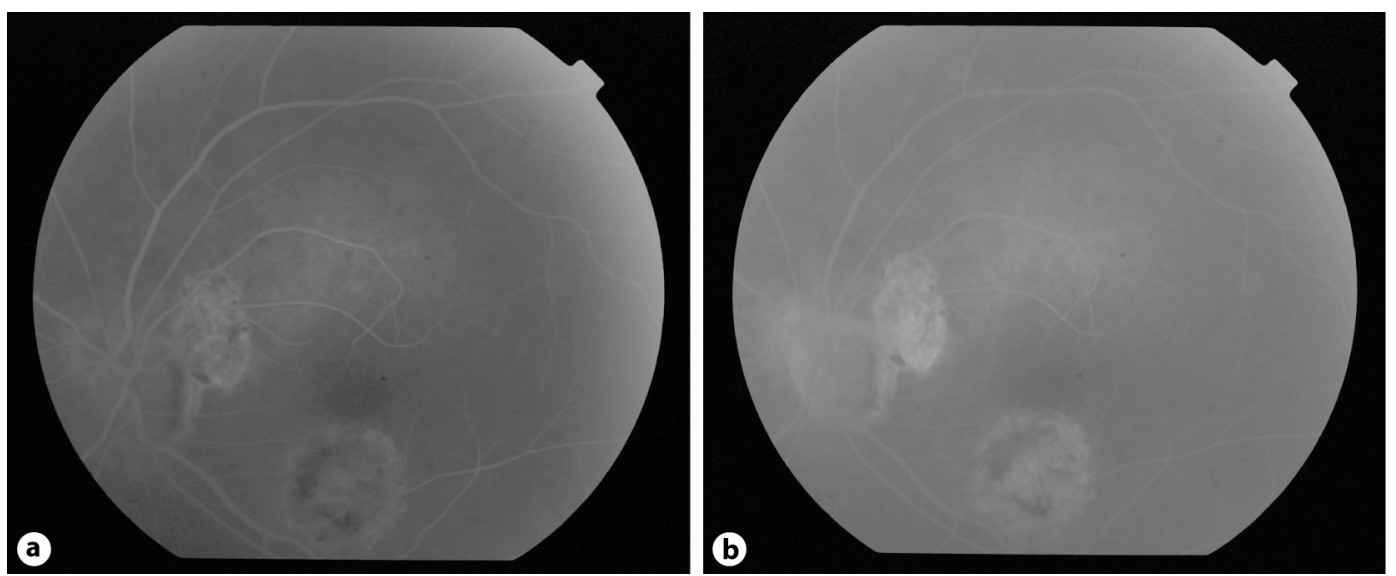

Fig. 6. a, b Fluorescein angiogram of the left eye at the 3rd month of cyclophosphamide therapy. Note the mottled hyperfluorescence due to pigment clumping in the early and late frames.

\section{References}

1 Laatikainen L, Erkkila H: Serpiginous choroiditis. Br J Ophthalmol 1974;58:777-783.

2 Abrez H, Biswas J, Sudharshan S: Clinical profile, treatment and visual outcome of serpiginous choroiditis. Ocular immunology and inflammation 2007;15:325-335.

-3 Vasconcelos-Santos DV, Rao K, Davies JB, Sohn EH, Rao NA: Clinical features of tuberculous serpiginouslike choroiditis in contrast to classic serpiginous choroiditis. Arch Ophthalmol 2010;128:853-858.

4 Akpek EK, Baltatzis S, Yang J, Foster SC: Long-term immunosuppressive treatment of serpiginous choroiditis. Ocular immunology and inflammation 2001;9:153-167.

5 Hooper PL, Kaplan HJ: Triple agent immunosuppression in serpiginous choroiditis. Ophthalmology 1991;98:944-952.

6 Akpek EK, Jabs DA, Tessler HH, Joondeph BC, Foster SC: Successful treatment of serpiginous choroiditis with alkylating agent. Ophthalmology 2002;109:1506-1513.

7 Sobacı G, Bayraktar Z, Bayer A: Interferon alpha-2a treatment for serpiginous choroiditis. Ocul Immunol Inflamm 2005;13:59-66. 